\title{
Systematic review: the epidemiology of ischaemic colitis
}

\author{
P. D. R. HIGGINS*, K. J. DAVIS $\uparrow \&$ L. LAINE $\ddagger$ \\ *University of Michigan, Ann Arbor, MI, USA; †GlaxoSmithKline, Research Triangle Park, NC, USA; \$University of \\ Southern California, Los Angeles, CA, USA
}

Accepted for publication 21 January 2004

\section{SUMMARY}

Background: Ischaemic colitis has been associated with co-morbid conditions, medications, vascular surgery and advanced age in case reports and case series. Few data exist on the baseline incidence in the general population or on the increased risk imposed by these risk factors.

Aim: To systematically review the literature regarding the incidence, prevalence and risk factors for ischaemic colitis.

Methods: Searches of bibliographic databases were performed independently by two investigators. Studies were included if they used population-based samples, disease-specific population samples or case-control population-based samples of adults with ischaemic colitis, and reported the incidence, prevalence or risk factors for ischaemic colitis. Eligible articles were reviewed and data were abstracted in a duplicate, independent manner.

Results: Four studies were identified that reported the general population incidence and four that reported the disease-specific population incidence. The incidence of ischaemic colitis in general populations ranged from 4.5 to 44 cases per 100000 person-years. The risk was increased two- to four-fold by either prevalent irritable bowel syndrome or chronic obstructive pulmonary disease. The risk was also increased in females and in subjects of 65 years and older.

Conclusions: Ischaemic colitis is uncommon in the general population. The effect sizes of the most commonly reported risk factors have not been adequately quantified in population-based studies.

\section{INTRODUCTION}

Ischaemic colitis is a vascular condition of inadequate blood flow in the colon which leads to colonic inflammation, and can produce significant morbidity and mortality. ${ }^{1-3}$ It is typically, although not exclusively, seen in elderly patients, and it may be increasing in incidence as the population ages. Multiple anecdotal case reports and case series have described associations of ischaemic colitis with vascular surgery and vascular thromboembolism, ${ }^{4-7}$ co-morbid medical conditions ${ }^{8-18}$ and medications including vasoconstrictors, psycho-

Correspondence to: Dr L. Laine, GI Division, Department of Medicine, U.S.C. School of Medicine, 2025 Zonal Ave., Los Angeles, CA 90033, USA.

E-mail: llaine@usc.edu

tropics, oral contraceptives, interferon- $\alpha$ and 5-hydroxytryptamine-1 $\left(5-\mathrm{HT}_{1}\right)$ agonists (triptans). ${ }^{19-25}$

Transient ischaemic colitis was first reported as a clinical finding in the 1960 s by Boley et al. ${ }^{26}$ and Marston et al. ${ }^{27}$ It has since become a well-recognized clinical entity, with well-characterized endoscopic ${ }^{28}$ and pathological $^{29}$ findings. Ischaemic colitis has recently become the subject of great controversy, as a new class of medications ( $5-\mathrm{HT}_{3}$ antagonists) has been associated with this condition, ${ }^{30}$ leading to the initial withdrawal by the Food and Drug Administration, and later restoration, of alosetron to the market in the USA. From studies assessing the incidence of ischaemic colitis in patients with irritable bowel syndrome, with and without alosetron therapy, ${ }^{30,31}$ a fundamental clinical question has been raised: "how common is ischaemic colitis in the general population?' It was our objective to 
systematically review the literature on ischaemic colitis and to summarize the available data on the baseline incidence and prevalence of this disease; data on potential risk factors that predispose to ischaemic colitis were also examined.

Determining the true incidence of ischaemic colitis poses some difficulty, as even vigilant clinicians with high-risk patients often miss the diagnosis. In two prospective series of patients, all of whom had endoscopy after aortic surgery, only half of those with colonic ischaemia confirmed by histopathology were clinically suspected to have ischaemic colitis by their surgeons. $^{32,33}$ A strict definition of ischaemic colitis would require biopsy confirmation of each diagnosis, although, in clinical practice, the criteria used to make a diagnosis of ischaemic colitis are likely to vary. However, even when the diagnosis is clinically suspected, and then confirmed by endoscopy and biopsy, finding these cases in an administrative or medical record database depends on appropriate coding for this unusual diagnosis.

It is important to determine the true incidence of ischaemic colitis in the population in order to understand the scope of the clinical problem, and to evaluate the true effects of the many medications that have been associated with ischaemic colitis. Knowledge of the epidemiology of ischaemic colitis is relevant to primary care providers, gastroenterologists and health care policy makers. However, no previous report has systematically reviewed the published literature on the epidemiology of ischaemic colitis.

Our purpose was to perform a systematic review of the published literature regarding the epidemiology of ischaemic colitis. Our specific study objectives were: (i) to determine the incidence and prevalence of ischaemic colitis; (ii) to determine the age, race and gender distribution of patients with ischaemic colitis; and (iii) to identify risk factors, such as medical co-morbidities, surgical procedures and medication use. This systematic review may also identify limitations of published research, allowing recommendations to be made for future research in this area.

\section{MATERIALS AND METHODS}

\section{Literature search}

A computer-assisted search using the OVID interface to MEDLINE, EMBASE and Current Contents was conducted to identify potentially relevant published papers. A search of the MEDLINE database from 1966 to the present was performed using the exploded (exp) medical subject heading (MeSH) terms (exp ischemic colitis OR ischemic colitis.mp OR colonic ischemia.mp) and (exp incidence OR exp prevalence OR exp epidemiology). An additional search for relevant titles was performed with the terms (ischemic colitis.ti OR colonic ischemia.ti) to ensure that any other relevant titles were not missed. We used both the terms 'ischemic colitis' and 'colonic ischemia' because they are used interchangeably in the medical literature; we use the term 'ischaemic colitis' throughout this article for consistency. The results were limited to human studies. An identical search of the biomedical and pharmaceutical EMBASE database from 1998 to Week 342003 was performed, and the results were limited to human studies. The Current Contents database from Week 27 1993 to Week 352003 was searched with the same criteria, but Current Contents is unable to limit to human studies. Manual searches of reference lists from potentially relevant papers were also performed to identify any additional studies that may have been missed using the computer-assisted strategy. Searches of abstracts from the last 5 years of annual meetings of the American College of Gastroenterology and American Gastroenterological Association and the last 4 years of meetings of the United European Gastroenterology Federation were performed to find potentially relevant data that have not yet been published. Prominent authors in the field and pharmaceutical companies with potential interest in the topic were contacted to enquire about any new data that were available, but not yet published.

\section{Study selection criteria}

Two investigators (P.D.R.H. and L.L.) independently reviewed the titles and abstracts of all citations identified by the literature search. Potentially relevant studies were retrieved and the selection criteria applied. The selection criteria were: (i) longitudinal studies of population-based samples of patients; (ii) adult patients; and (iii) results reported on the incidence, prevalence and demographics of, or risk factors for, ischaemic colitis.

As there was an expectation that there might be very few articles that met these criteria, an option of expanded criteria was planned, if necessary, to include disease-specific population-based cohort studies, general 
or disease-specific population-based case-control studies and case series drawn from a defined catchment area with more than 100 cases.

\section{Data extraction and data analysis}

The eligible articles were reviewed in a duplicate, independent manner by two investigators (P.D.R.H. and L.L.). Agreement on the selection of studies was $100 \%$. Data abstraction on pre-designed and pre-tested forms was also performed in a duplicate, independent fashion by the two investigators. Agreement between the investigators was greater than $97 \%$, and disagreement in data extraction was resolved by consensus. For studies regarding the incidence of ischaemic colitis, the incidence, race distribution, gender distribution, age distribution and associated medical and surgical co-morbidities and medications were extracted, if available. For these incidence studies, data on the diagnostic definitions of ischaemic colitis, sample size and case ascertainment techniques (e.g. administrative data, chart review, prospective cohort follow-up and requirement for endoscopy or histopathology) were also extracted.

\section{RESULTS}

\section{Characteristics of selected studies}

Searching the MEDLINE database yielded 22 articles in the MeSH search and 470 articles in the titles search; the EMBASE database yielded 77 and 271 articles and the Current Contents database yielded 38 and 132 articles with the above-described searches. There were several articles found in more than one search, and a net total of 639 articles was found. A further 32 candidate studies were identified by reviewing the abstracts of recent gastroenterology annual meetings. The titles and abstracts of these 671 articles were reviewed by two authors (P.D.R.H. and L.L.).

The literature search identified only two relevant population-based studies that met our initial criteria. $^{34,} 35$ Two additional studies that have not yet been published [large US health maintenance organization (HMO), General Practice Research Database (GPRD)] were obtained through personal communication. $^{36,37}$ Because of this paucity of data, the option to broaden the criteria was activated. Four illness-specific studies $^{31,35-37}$ and a case-control study that reported risk factors for ischaemic colitis in a general patient population $^{38}$ were identified. No case series of more than 100 cases from a defined catchment area was found. Only one of the selected studies has been published in full manuscript form, ${ }^{31}$ while three have been published in abstract form. ${ }^{34,} 35,38$

\section{Studies of incidence of ischaemic colitis in the general} population

Four studies determined the incidence rates in the general population, and these are summarized in Table 1. Loftus et al. studied all residents of Olmsted County, Minnesota, USA. ${ }^{34}$ They did not report the total number of residents followed in the abstract, but 173 cases were reported between January 1, 1976 and December 31, 1998. The cases were considered to be definite if confirmatory histopathology was available, and probable if chart review of endoscopic or radiological findings was compatible with the diagnosis of ischaemic colitis. Amongst all the cases, 64\% were female and the median age was 70.6 years. The incidence rates were adjusted for age and gender in a Poisson regression model, and were 6.1 per 100000 person-years for definite cases and 9.9 per 100000 person-years for all cases (definite and probable).

Cole et al. evaluated 1\% of the population of a large US national HMO. ${ }^{35}$ The total number of subjects was not reported, but their records were reviewed from January 1995 to December 1999. Cases were defined on the basis of claims data for diagnoses, procedures and drugs, but specific diagnostic criteria were not reported. Findings were confirmed by chart review. The number of cases was reported as approximately $90 \%$ of 714 . The percentage of females and the age and race distribution of the patients were not reported. The incidence rate was adjusted for age, gender and calendar year in a Poisson regression model. The adjusted incidence rates were 9 cases per 100000 person-years for women and 5 cases per 100000 person-years for men.

A study of the large UK GPRD evaluated 430574 individuals without physician-diagnosed chronic obstructive pulmonary disease (COPD) from January 1987 to December 2000, with an average of 5.4 years of follow-up data per patient. ${ }^{36}$ These patients had been age-, gender- and practice-matched to 59447 patients with physician-diagnosed COPD, leading to a group with older average age than a general population study. 
Table 1. The incidence of ischaemic colitis in studies of the general population

\begin{tabular}{|c|c|c|c|c|c|c|c|c|c|}
\hline Reference & Population & $n$ & Time period & Follow-up & Case definition & $\begin{array}{l}\text { Incident } \\
\text { cases }\end{array}$ & $\begin{array}{l}\text { Females } \\
(\%)\end{array}$ & $\begin{array}{l}\text { Mean age } \\
\text { (years) }\end{array}$ & $\begin{array}{l}\text { Incidence per } 100000 \\
\text { person-years }\end{array}$ \\
\hline Loftus et al. ${ }^{34}$ & $\begin{array}{l}\text { Olmsted } \\
\text { County }\end{array}$ & NR & $1 / 1 / 76-12 / 31 / 98$ & NR & $\begin{array}{l}\text { Endoscopic or radiological } \\
\text { findings (probable) or } \\
\text { histopathology (definite) }\end{array}$ & 173 & 64 & $70.6^{*}$ & $9.9 \dagger$ \\
\hline Cole et $a .^{35}$ & US HMO & $\begin{array}{l}1 \% \text { of } \\
\text { membership }\end{array}$ & $1 / 95-12 / 99$ & NR & $\begin{array}{l}\text { Claims data on diagnoses, } \\
\text { procedures, and drugs } \\
\text { Validated by chart review }\end{array}$ & $\begin{array}{l}\approx 90 \% \\
\quad \text { of } 714\end{array}$ & NR & NR & $\begin{array}{c}\text { Women: } 9 \dagger \\
\text { Men: } 5 \dagger\end{array}$ \\
\hline Davis et al. ${ }^{36}$ & UK GPRD & 430574 & $1 / 87-12 / 00$ & $\begin{array}{l}1275955 \\
\text { person-years }\end{array}$ & $\begin{array}{l}\text { READ and OXMIS diagnostic } \\
\text { codes for ischaemic colitis } \\
\text { among patients without } \\
\text { COPD diagnosis }\end{array}$ & 57 & 61.4 & 75.1 & $4.47(95 \%$ CI, 3.38-5.79) \\
\hline Davis et al. ${ }^{37}$ & $\begin{array}{l}\text { US HMO } \\
\quad>40 \text { years }\end{array}$ & 15864 & $1 / 1 / 97-6 / 30 / 01$ & $\begin{array}{l}18025.45 \\
\text { person-years }\end{array}$ & $\begin{array}{l}\text { Diagnosis of vascular } \\
\text { insufficiency (ICD9 code 557) } \\
\text { within } 3 \text { months of colonoscopy, } \\
\text { colectomy or histopathological } \\
\text { examination of colon among } \\
\text { patients without COPD; } \\
\text { minimum } 12 \text { months in } \\
\text { health plan }\end{array}$ & 8 & 55 & $60-64^{*}$ & $44(95 \%$ CI, 19-87) \\
\hline
\end{tabular}

CI, confidence interval; COPD, chronic obstructive pulmonary disease; GPRD, General Practice Research Database; HMO, health maintenance organization; ICD9, International Classification of Diseases, Ninth Revision: NR, not reported; OXMIS, Oxford Medical Indexing System.

* Reported median age of cases.

$\dagger$ Incidence adjusted for age, gender and calendar year 
Prevalent cases were defined as cases that had an ischaemic colitis diagnostic code at any time during 1987-2000, and incident cases as those that occurred after a randomly assigned index date. The crude prevalence was 19.28 per 100000 persons; $63 \%$ were female, the mean age was 77.0 years and $47 \%$ died during the study period. The crude incidence rate was 4.47 per 100000 years [95\% confidence interval (CI), 3.38-5.79]; $61 \%$ were female, the mean age was 75.1 years and $56 \%$ died during the study period. A large proportion of diagnoses were reportedly made at the time of death.

Data from a study of a US HMO evaluated 15864 individuals aged 40 years and older, with a minimum of 12 months enrolment in the health plan, and without any health care claims for COPD. ${ }^{37}$ This group of patients was a comparison cohort that was age- and gender-matched to patients with COPD, leading to a study cohort enriched in patients older than the general population. The cases were defined as patients with a diagnosis of vascular insufficiency of the intestine [International Classification of Diseases, Ninth Revision (ICD9): code 557] within 3 months after colonoscopy, colon resection or histopathological examination of a colon specimen. Patients with non-infectious gastroenteritis or colitis and a diagnosis, within 2 weeks of the vascular insufficiency diagnosis, of Clostridium difficile, Crohn's disease, ulcerative colitis, small bowel resection or the use of 5-aminosalicylates were excluded. The crude incidence rate was 44 cases per 100000 personyears (95\% CI, 19-87). A separate analysis that required only 6 months of enrolment studied 32325 individuals, and found a crude incidence rate of 34 cases per 100000 person-years (95\% CI, 17-60).

\section{Studies of incidence of ischaemic colitis in specific diseases}

Four studies looked in detail at the incidence of ischaemic colitis in specific diseases (Table 2): two in patients with irritable bowel syndrome and two in patients with COPD. Miller et al. evaluated records for 6111 patients in a large US HMO, all of whom had a diagnosis of irritable bowel syndrome before December 2000. ${ }^{31}$ Any patient with a coincident diagnosis of Crohn's disease, ulcerative colitis, colorectal cancer, chronic pancreatitis, pancreatic cancer, liver cirrhosis, coeliac disease, intestinal malabsorption syndromes or ovarian cancer was excluded. The length of follow-up appeared to be from March 2000 to December 2000.
Candidate ischaemic colitis cases were considered if they had a diagnosis code (ICD9: 557) for vascular insufficiency of the intestine on the same day, or within 3 months, of colonoscopy or colectomy. Abstracted records were reviewed by a gastroenterologist and cases were considered to be positive for ischaemic colitis if the 'available clinical evidence was more substantially consonant with [ischaemic colitis] than any other diagnosis'. In this study, no cases of ischaemic colitis were identified in irritable bowel syndrome patients. The reported 95\% CIs for the incidence of ischaemic colitis were 0 to 341 cases per 100000 patient-years in patients not taking alosetron $(n=2480)$, and 0 to 228 cases per 100000 patient-years for alosetron users $(n=3631)$.

In the study by Cole et al. discussed above, a second arm evaluated the incidence in patients with irritable bowel syndrome, using the same US HMO data source and the same case definitions. ${ }^{35}$ A total of 87449 irritable bowel syndrome patients were evaluated from January 1995 to December 1999. The number of incident cases was reported as approximately $10 \%$ of 714. The incidence rates per 100000 person-years were 46 for women and 30 for men in the first year after an irritable bowel syndrome diagnosis. After adjustment for age and gender in the Poisson regression model, the relative risk for ischaemic colitis in patients during the year following a diagnosis of irritable bowel syndrome was 3.1 (95\% CI, 2.1-4.6).

The UK GPRD study by Davis et al. evaluated patients with COPD in a second arm. ${ }^{36}$ A cohort of 59447 COPD patients was compared with 430574 age-, gender- and practice-matched controls. Incident cases were defined by the first code for ischaemic colitis occurring after the initial diagnosis code for COPD. There were 17 incident cases over an average follow-up of 6.2 years. The incidence was 9.2 per 100000 person-years (vs. 4.5 in the non-COPD cohort); the relative risk of ischaemic colitis in individuals with COPD was 2.16 (95\% CI, 1.26-3.71). The majority of cases were female $(59 \%$ in COPD and $61 \%$ in nonCOPD) and elderly (mean age: 75.1 years in COPD and 73.5 years in non-COPD). The prevalence rate in COPD patients was 50.0 cases of ischaemic colitis per 100000 patients (vs. 19.3 for non-COPD), creating a relative risk of 2.62 (95\% CI, 1.72-3.97).

The large US HMO study presented above also had a second arm, in which 15849 patients over 40 years with COPD were evaluated as described above, and 
Table 2. The incidence of ischaemic colitis in disease-specific population studies

\begin{tabular}{|c|c|c|c|c|c|c|c|c|c|c|}
\hline Reference & Disease & $n$ & Time period & Follow-up & Case definition & $\begin{array}{l}\text { Incident } \\
\text { cases }\end{array}$ & $\begin{array}{l}\text { Females } \\
(\%)\end{array}$ & $\begin{array}{l}\text { Mean age } \\
\text { (years) }\end{array}$ & $\begin{array}{l}\text { Incidence per } 100000 \\
\text { person-years }(95 \% \mathrm{CI})\end{array}$ & $\begin{array}{l}\text { RR (vs. general } \\
\text { population) }(95 \% \mathrm{CI})\end{array}$ \\
\hline Miller et al. ${ }^{31}$ & $\begin{array}{l}\text { IBS in } \\
\text { US HMO }\end{array}$ & 6111 & $\begin{array}{l}3 / 00- \\
12 / 31 / 00\end{array}$ & $\begin{array}{l}\text { Average } \\
161 \text { days }\end{array}$ & $\begin{array}{l}\text { ICD9 code } 557 \text {, within } \\
3 \text { months of colonoscopy } \\
\text { or colectomy, evaluated } \\
\text { by record review }\end{array}$ & 0 & NR & NR & $0(0-341)^{*}$ & NR \\
\hline Cole et al. ${ }^{35}$ & $\begin{array}{l}\text { IBS in } \\
\text { US HMO }\end{array}$ & 87449 & $\begin{array}{l}1 / 95- \\
12 / 99\end{array}$ & NR & $\begin{array}{l}\text { Claims data on } \\
\text { diagnoses, procedures, } \\
\text { and drugs. Validated by } \\
\text { chart review }\end{array}$ & $\begin{array}{l}\approx 10 \% \\
\quad \text { of } 714\end{array}$ & NR & NR & $\begin{array}{l}46 \text { in women, } \\
30 \text { in men } \\
\text { in first year post-IBS } \\
\text { diagnosis }\end{array}$ & $3.1 \dagger(2.1-4.6)$ \\
\hline Davis et al. ${ }^{36} \ddagger$ & $\begin{array}{l}\text { COPD in } \\
\text { UK GPRD }\end{array}$ & 59434 & $\begin{array}{l}1 / 87 \\
-12 / 00\end{array}$ & $\begin{array}{l}184652 \\
\text { person-years }\end{array}$ & $\begin{array}{l}\text { READ and OXMIS } \\
\text { diagnostic codes for } \\
\text { ischaemic colitis, } \\
\text { occurring after first } \\
\text { diagnosis of COPD }\end{array}$ & 17 & 59 & 73.5 & $9.21(5.36-14.74)$ & $2.16(1.26-3.71)$ \\
\hline Davis et al. ${ }^{37}+$ & $\begin{array}{l}\text { COPD in } \\
\text { US HMO }\end{array}$ & 15849 & $\begin{array}{l}\text { 1/1/97- } \\
\text { 6/30/01 }\end{array}$ & $\begin{array}{l}19710 \\
\text { person-years }\end{array}$ & $\begin{array}{l}\text { Diagnosis of vascular } \\
\text { insufficiency of intestine } \\
\text { (ICD9 code 557) within } \\
3 \text { months of colonoscopy, } \\
\text { colectomy or } \\
\text { histopathological } \\
\text { examination of colon; } \\
\text { minimum } 12 \text { months } \\
\text { in health plan }\end{array}$ & 31 & 62 & $60-64 \S$ & 157 (107-223) & $3.88(1.78-8.44)$ \\
\hline
\end{tabular}

CI, confidence interval; COPD, chronic obstructive pulmonary disease; GPRD, General Practice Research Database; HMO, health maintenance organization; IBS, irritable bowel syndrome; ICD9, International Classification of Diseases, Ninth Revision; NR, not reported; OXMIS, Oxford Medical Indexing System; RR, relative risk.

* $97.5 \%$ one-sided CI reported.

$\dagger$ Incidence adjusted for age, gender and calendar year.

\$ 'General population' cohorts matched on age, sex and practice for UK GPRD or health plan for large US HMO study.

$\S$ Reported median age of cases. 
compared with age- and gender-matched controls. ${ }^{37}$ The crude incidence rate was 157 per 100000 personyears (95\% CI, 107-223), with a relative risk of ischaemic colitis in patients with COPD of 3.88 (95\% CI, 1.78-8.44). The analysis that required only 6 months of enrolment studied 32301 individuals, and found a crude incidence rate of 117 cases per 100000 person-years (95\% CI, 86-155), with a relative risk of ischaemic colitis in patients with COPD of 4.28 (95\% CI, 2.22-8.24).

\section{Studies of risk factors for ischaemic colitis}

Cole et al. reported a higher incidence of ischaemic colitis in women than in men in patients without irritable bowel syndrome ( 9 vs. 5 per 100000 personyears) and with irritable bowel syndrome (46 vs. 30 per 100000 person-years). ${ }^{35}$ The large US HMO study presented incidence rates of ischaemic colitis by age strata and gender. ${ }^{37}$ Women without COPD had an incidence of 44 cases per 100000 person-years, whilst the incidence in men without COPD was 32 cases per 100000 person-years. In the COPD population, the incidence rates for women and men were 157 and 98 per 100000 person-years. In individuals without COPD, the incidence in the youngest age stratum (40-49 years) was zero, compared with 119 per 100000 person-years for subjects $\geq 65$ years. The incidences in the COPD population were 74 per 100000 person-years for the 40-49-year age group and 373 per 100000 person-years for those aged $\geq 65$ years.

In the Olmsted County study, Loftus et al. found that a later calendar year was associated with higher rates of ischaemic colitis. ${ }^{34}$ Comparing 1994-1998 with 1976 1978, the incidence rates per 100000 person-years were 12.3 and 3.3 for all cases, and 8.1 and 2.2 for definite (histopathologically proven) cases. This represents an increase of 3.73-fold for all cases and 3.68-fold for definite cases over 20 years.

A population-based case-control study of ischaemic colitis evaluating risk factors was reported by Bohn et al. ${ }^{38}$ A large medical claims database was used to select 697 cases of ischaemic colitis (case definition not provided) occurring between 1995 and 1999; 6440 controls were randomly selected from the same health plans. A logistic regression model was used to adjust for age, gender, region and calendar time. The odds ratio for ischaemic colitis in irritable bowel syndrome patients vs. controls was 10.8 (95\% CI, 7.1-16.3). The odds ratios for additional variables were reported, although without CIs. The largest odds ratios were almost seven for a diagnosis of non-specific colitis in the previous 6 months, seven for visiting a gastroenterologist in the previous 6 months, six for abdominal surgery in the previous month, and approximately two for constipating medications. Non-steroidal anti-inflammatory drugs had an odds ratio of approximately 0.5 (they were protective) for ischaemic colitis.

\section{DISCUSSION}

This systematic review of the epidemiology of ischaemic colitis found that relatively few studies have been performed on the subject. We found only four general population studies meeting our criteria - none of which had been published in full manuscript form. The incidence of ischaemic colitis in the general population in these studies ranged from 4.5 to 44 cases per 100000 person-years. Three of the studies were relatively homogeneous in their estimates of the incidence, with a range of 4.5-9.9 per 100000 person-years, whereas the large US HMO study reported estimates 5-10-fold higher than the other studies.

It is possible that the population in the large US HMO study, by being restricted to those over 40 years of age and age-matched to COPD patients (who are likely to be older than the general population and the irritable bowel syndrome population), has important differences in baseline risk compared with the populations in the other two US studies. However, the GPRD study, which was much larger and similarly restricted to agematched controls of COPD patients, also had an incidence of ischaemic colitis that was 10-fold lower than that observed in the large US HMO study. The GPRD study may have markedly underestimated the number of ischaemic colitis cases by depending only on those recorded by the general practitioner (possibly only identifying the most severe cases, as suggested by the fact that a large proportion of patients had their diagnosis made at the time of death). Furthermore, the GPRD study included patients from earlier years than the large US HMO study, and an earlier calendar year was reported to be associated with a lower incidence of ischaemic colitis by Loftus et al. ${ }^{34}$ Alternatively, the large US HMO study may have overestimated the number of ischaemic colitis cases due to their 
use of diagnostic coding from an administrative claims database without substantiation of these diagnoses from medical records.

The criteria for a diagnosis of ischaemic colitis also varied between studies. Loftus et al. used the strictest criteria for their 'definite' cases, requiring histological confirmation of ischaemic colitis. ${ }^{34}$ They also had a category of 'probable' ischaemic colitis, in which other clinical findings, without histological evidence of ischaemic colitis, were sufficient for the diagnosis. It is important to note that just over one-third of cases are excluded by the requirement for histopathology, indicating that studies with this more stringent definition will have lower incidences than studies in which other clinical evidence (without histological examination) is used to diagnose ischaemic colitis. The more liberal definition may overstate the incidence as some of the cases without histopathology may not be ischaemic colitis, whereas the more stringent definition may understate the incidence because histological examination may not have been performed or may not have been diagnostic in some cases of true ischaemic colitis.

We evaluated four studies that examined the effects of co-morbid diseases on the incidence of ischaemic colitis; only one of these studies had been published as a full manuscript. ${ }^{31}$ Because it has been speculated that some drugs, such as those used to treat irritable bowel syndrome and COPD, may cause ischaemic colitis, it is worthwhile to determine whether there is any increase in the incidence of ischaemic colitis in patients with specific illnesses. Compared with the general population, the relative risk for ischaemic colitis in irritable bowel syndrome patients was increased approximately threefold, ${ }^{35}$ whereas the increase in COPD patients was about two to four-fold. ${ }^{36,37}$ Thus, both irritable bowel syndrome and COPD appear to be associated with significant increases in the incidence of ischaemic colitis, as measured in retrospective studies of health care databases.

Constipation is another co-morbidity that appears to be a risk factor for ischaemic colitis. Irritable bowel syndrome can be associated with significant constipation in patients with the constipation-predominant subtype. Multiple case series have described constipation as a risk factor for ischaemic colitis ${ }^{16-18}$ and constipating medications were noted as a risk factor (two-fold increase) in Bohn et al.'s case-control study. ${ }^{38}$ Constipation is believed to promote ischaemia by increasing intraluminal pressure and compressing the mucosal vessels. ${ }^{39}$
The reasons for the association between ischaemic colitis and COPD are unclear. Most patients with COPD have a considerable lifetime exposure to cigarette smoking; hence they also experience an increased incidence of cardiovascular disease, which has been described as a risk factor for ischaemic colitis in a number of case series. ${ }^{40}$ It is also possible that the hypoxaemia associated with the chronic pulmonary disease process could contribute more directly to ischaemic colitis. These mechanisms warrant further study.

Age and female gender also seem to increase the risk of ischaemic colitis. For example, in subjects without COPD in the large US HMO study, the rate of ischaemic colitis increased from zero for individuals in their forties to 119 per 100000 person-years in patients aged $\geq 65$ years, and the rate for women was nearly double the rate for men (58 vs. 32 per 100000 personyears). ${ }^{37}$ Cole $e t$ al. also found an approximately 1.5-2fold higher incidence of ischaemic colitis for women vs. men in the irritable bowel syndrome and non-irritable bowel syndrome populations. ${ }^{35}$ However, statistical comparisons related to age or gender were not presented in any of the studies.

The data on the incidence of ischaemic colitis found in the literature have several limitations. Most of the studies have not yet been published in full manuscript form. No data were available on race or ethnicity from studies conducted on health care data sources, and data on patient demographics or length of follow-up were not consistently reported. Many risk factors have been described in case series, but these were infrequently measured in the descriptive studies. Another important consideration is the aggressiveness of care givers in seeking this diagnosis with endoscopy. Prospective surgical studies suggest that ischaemic colitis is often unsuspected, even in high-risk patients after abdominal vascular surgery. ${ }^{32,33}$ More aggressive work-up and diagnosis over time may have contributed to the increased incidence seen in the 1990s in the study by Loftus et al., ${ }^{34}$ and may have contributed to the differences observed between the incidence rates in the UK and US COPD studies.

Ideally, future studies of the incidence of ischaemic colitis should address all of these limitations. They should be population-based, with case ascertainment that includes medical record review. In addition, risk factors, including vascular disease, vascular surgery, 
co-morbid rheumatological diseases, predisposition to venous thromboembolism, constipation, irritable bowel syndrome, bowel obstruction and medications thought to confer risk, should be measured and reported. These studies would provide an accurate assessment of the incidence of ischaemic colitis in the general population, and would assess the importance of covariate risk factors. This level of information is critical for the assessment of whether the observed incidence of ischaemic colitis with new medications is truly increased from the observed baseline incidence in the study population.

Another important aspect of the epidemiology of ischaemic colitis lies in its association with increasing age. As the population ages, there may be a significant increase in incidence and associated major morbidity and mortality from ischaemic colitis. It will become more important to identify patients at increased risk, as a high index of suspicion is needed to make this diagnosis. To be able to do this, we need to have better data on the baseline incidence at a given age, and on which additional patient characteristics and medications increase the risk. Although there is no current standard therapy for ischaemic colitis beyond supportive care, new research in this area raises the hope that this may change in the near future. ${ }^{41-43}$ With this in mind, our review documents the need for renewed efforts towards well-designed research into the incidence and risk factors for ischaemic colitis. With the ageing of our population, clinicians and researchers should devote more resources to the previously neglected area of gastroenterological disease in the elderly.

\section{ACKNOWLEDGEMENTS}

Dr Higgins is supported by the NIH T32 Training Grant in Gastroenterology Outcomes Research DK62708-01 at the University of Michigan.

Dr Davis is an employee of GlaxoSmithKline.

Dr Laine has served as a consultant to GlaxoSmithKline and Novartis.

\section{REFERENCES}

1 Klempnauer J, Grothues F, Bektas H, Pichlmayr R. Long-term results after surgery for acute mesenteric ischemia. Surgery 1997; 121(3): 239-43.
2 Longo WE, Ward D, Vernava AM 3rd, Kaminski DL. Outcome of patients with total colonic ischemia. Dis Colon Rectum 1997; 40(12): 1448-54.

3 Guttormson NL, Bubrick MP. Mortality from ischemic colitis. Dis Colon Rectum 1989; 32(6): 469-72.

4 Jarvinen O, Laurikka J, Salenius JP, Lepantalo M. Mesenteric infarction after aortoiliac surgery on the basis of 1752 operations from the national vascular registry. World J Surg 1999; 23(3): 243-7.

5 Bjorck M, Bergqvist D, Troeng T. Incidence and clinical presentation of bowel ischaemia after aortoiliac surgery 2930 operations from a population-based registry in Sweden. Eur J Vasc Endovasc Surg 1996; 12(2): 139-44.

6 Collet T, Even C, Bouin M, et al. Prevalence of electrocardiographic and echocardiographic abnormalities in ambulatory ischemic colitis. Dig Dis Sci 2000; 45(1): 23-5.

7 Hourmand-Ollivier I, Bouin M, Saloux E, et al. Cardiac sources of embolism should be routinely screened in ischemic colitis. Am J Gastroenterol 2003; 98(7): 1573-7.

8 Green BT, Branch MS. Ischemic colitis in a young adult during sickle cell crisis: case report and review. Gastrointest Endosc 2003; 57(4): 605-7.

9 Kistin MG, Kaplan MM, Harrington JT. Diffuse ischemic colitis associated with systemic lupus erythematosus - response to subtotal colectomy. Gastroenterology 1978; 75(6): 114751.

10 Perez-Aguilar F, Lacruz J, Verdu RC, et al. Rheumatoid vasculitis presented as abscessified splenic infarcts, ischemic colitis, angor pectoris and peripherical polyneuropathy [in Spanish]. Rev Esp Reumatol 1991; 18(9): 349-52.

11 Yee NS, Guerry DT, Lichtenstein GR. Ischemic colitis associated with factor V Leiden mutation. Ann Intern Med 2000; 132(7): 595-6.

12 Richardson SC, Willis J, Wong RCK. Ischemic colitis, systemic lupus erythematosus, and the lupus anticoagulant: case report and review. Gastrointest Endosc 2003; 57(2): 257-60.

13 Tsuda N, Satomi S, Oka S, et al. A case of colonic cancer complicated with ischemic colitis [in Japanese]. Endosc Forum Digest Dis 2000; 16(2).

14 Kikuchi R, Takano M, Fujiyoshi T, et al. A clinical study of ischemic colitis [in Japanese]. J Jpn Soc Colo Proctol 1994; 47(1): 23-30.

15 Byrd RL, Cunningham MW, Goldman LI. Nonocclusive ischemic colitis secondary to hemorrhagic shock. Dis Colon Rectum 1987; 30(2): 116-8.

16 Habu Y, Tahashi Y, Kiyota K, et al. Reevaluation of clinical features of ischemic colitis - analysis of 68 consecutive cases diagnosed by early colonoscopy. Scand J Gastroenterol 1996; 31(9): 881-6.

17 Matsumoto T, Iida M, Kimura Y, Nanbu T, Fujishima M. Clinical features in young adult patients with ischaemic colitis. J Gastroenterol Hepatol 1994; 9(6): 572-5.

18 Kurumada T, Machida M, Deguchi R, Kohda K, Hasebe T, Miwa T. [Age-related clinical features in ischemic colitis]. Nippon Ronen Igakkai Zasshi 2000; 37(5): 388-92. 
19 Patel YJ, Scherl ND, Elias S, Chessler RK, Zingler BM. Ischemic colitis associated with psychotropic drugs. Digest Dis Sci 1992; 37(7): 1148-9.

20 Johnson TD, Berenson MM. Methamphetamine-induced ischemic colitis. J Clin Gastroenterol 1991; 13(6): 687-9.

21 Brown DN, Rosenholtz MJ, Marshall JB. Ischemic colitis related to cocaine abuse. Am J Gastroenterol 1994; 89(9): 155861.

22 Iversen E, Wied U. [Ischemic colitis and ergotamine abuse]. Ugeskr Laeg 1986; 148(12): 718-9.

23 Deana DG, Dean PJ. Reversible ischemic colitis in young women - association with oral contraceptive use. Am J Surg Pathol 1995; 19(4): 454-62.

24 Knudsen JF, Friedman B, Chen M, Goldwasser JE. Ischemic colitis and sumatriptan use. Arch Intern Med 1998; 158(17): 1946-8.

25 Tada H, Saitoh S, Nakagawa Y, et al. Ischemic colitis during interferon-alpha treatment for chronic active hepatitis C. J Gastroenterol 1996; 31(4): 582-4.

26 Boley SJ, Schwartz S, Lash J, Sternhill V. Reversible vascular occlusion of the colon. Surg Gynecol Obstet 1963; 116: 5360.

27 Marston A, Pheils MT, Thomas ML, Morson BC. Ischaemic colitis. Gut 1966; 7: 1-15.

28 Forde KA, Lebwohl O, Wolff M, Voorhees AB. The endoscopy corner: reversible ischemic colitis - correlation of colonoscopic and pathologic changes. Am J Gastroenterol 1979; 72(2): 182-5.

29 Dignan CR, Greenson JK. Can ischemic colitis be differentiated from $C$. difficile colitis in biopsy specimens. Am J Surg Pathol 1997; 21(6): 706-10.

30 Friedel D, Thomas R, Fisher RS. Ischemic colitis during treatment with alosetron. Gastroenterology 2001; 120(2): 557-60.

31 Miller DP, Alfredson T, Cook SF, Sands BE, Walker AM. Incidence of colonic ischemia, hospitalized complications of constipation, and bowel surgery in relation to use of alosetron hydrochloride. Am J Gastroenterol 2003; 98(5): 1117-22.

32 Welch M, Baguneid MS, McMahon RF, et al. Histological study of colonic ischaemia after aortic surgery. Br J Surg 1998; 85(8): 1095-8.
33 Fanti L, Masci E, Mariani A, et al. Is endoscopy useful for early diagnosis of ischaemic colitis after aortic surgery? Results of a prospective trial. Ital J Gastroenterol Hepatol 1997; 29(4): 357-60.

34 Loftus EV, Sandborn WJ, Tremaine WJ, et al. Incidence of ischemic colitis in Olmsted County, Minnesota, 1976-1998. Am J Gastroenterol 2002; 97(9): S121-22(Abstract 368).

35 Cole JA, Cook SF, Miller DP, et al. The risk of colonic ischemia among patients with irritable bowel syndrome. Digestive Disease Week 2002: A91(Abstract 726).

36 Davis KJ, Clark DW, Visick G, Soriano JB, Reisner C. Prevalence and incidence of colon ischemia in COPD patients in the UK. Analysis of the General Practice Research Database. Presented at the American Geriatrics Society Meeting, May 2003, Baltimore, MD, USA.

37 Davis KJ, Walker AM. Incidence of colon ischemia and perforated intestine in COPD patients: a matched cohort analysis. Submitted.

38 Bohn RL, Cali C, Cook S, Sands BE, Walker AM. Risk factors for colonic ischemia. Digestive Disease Week 2002: A437(Abstract T1228).

39 Beck IT. Possible mechanisms for ischemic colitis during alosetron therapy. Gastroenterology 2001; 121(1): 231-2.

40 Aracil CDA, Velasco RV, Perez VE, del Campo IV, del Olmo AG. Ischaemic colitis. Descriptive analysis in a Madrid hospital. Rev Clin Esp 1998; 198(11): 726-9.

41 Otte JA, Geelkerken RH, Huisman AB, Kolkman JJ. Diagnosis and treatment of chronic gastrointestinal ischemia. A multidisciplinary team approach: the Enschede cohort. Gut 2001; 49(S3): Abstract 2974.

42 Mensink PBF, Kolkman JJ, Otte JA, Geelkerken RH, Huisman AB. Gastric or mesenteric ischemia by stenosis of only one mesenteric artery? Clinical picture, treatment, and follow-up in 22 patients. Gut 2001; 49(S3): Abstract 2587.

43 Kimura M, Tanaka M. A new treatment of stricture type ischemic colitis by continuous intravenous infusion of prostaglandin E1. Gut 2002; 51(S3): Abstract 267. 